\title{
BUDAYA, AGAMA, DAN MAKNA VOLUNTERISME BAGI KADER WARGA PEDULI AIDS DI KOTA BANDUNG
}

\author{
Ema Herawat ${ }^{1 *}$ \\ ${ }^{1}$ Department of Anthropology, Faculty of Social and Political Science, Padjadjaran University
}

\section{ARTICLE INFORMATION}

Submitted : 28 April 2019

Review : 19 August 2019

Accepted : 21 November 2019

Available online: December 2019

\section{KEYWORDS}

Budaya; Agama; Volunterisme; Warga Peduli AIDS

\section{CORRESPONDENCE}

*E-mail: e.herawati@unpad.ac.id

\section{A. PENDAHULUAN}

stilah Warga Peduli AIDS (selanjutnya disingkat WPA) merujuk pada gerakan atau aksi oleh warga masyarakat sebagai wujud kepedulian dan partisipasi mereka dalam upaya mengatasi masalah HIV dan AIDS di wilayah tempat tinggal masing-masing (Komisi Penanggulangan AIDS Nasional, 2010). Pembentukan WPA diatur dalam PERMENKES RI No. 21 tahun 2013 bab XI pasal 51 ayat 1 (d) yang berbunyi: "Masyarakat dapat berperan serta dalam upaya Penanggulangan HIV/AIDS dengan acara membentuk dan mengembangkan WPA". WPA terdiri dari berbagai komponen di lingkungan masyarakat baik di tingkat Desa, Kelurahan, Rukun Warga (RW), Dusun, Blok dan tingkat sejenisnya. Bentuk gerakan WPA di dalam pelaksanaannya cukup beragam di setiap wilayah, tergantung dari situasi dan kondisi (Kementerian Kesehatan Republik Indonesia, 2013). Tugas utama para warga yang tergabung dalam gerakan WPA (selanjutnya disebut kader

\section{A B S T R A C T}

HIV epidemic in Indonesia has been last for three
decades and the members of the community have
participated in the prevention and intervention. Warga
Peduli AIDS (WPA) is an action by a group of local
residents in Bandung City who concerned about HIV and
AIDS. This action has been one of examples of
community participation in responding to the epidemic.
The action includes participation in meetings held by
NGOs and city government to discuss prevention at the
community level, dissemination of information about
epidemic preventions; and providing social support for
people living with HIV and AIDS. This study aims at
describing motives that drive the WPA activist (better
known as WPA Kader) to carry out an action, and how
they view the meaning of their action. This study was
conducted in a qualitative approach using an ethnog-
raphic model. This study finds that WPA Kader derived
their motive of action from religious and cultural values,
and their action is a combination of altruism and self-
interest to pursue their personal spiritual satisfaction. In
line with this motive, they view their action as part of
their religious and cultural expression; instead of merely
a community-based action to respond to a timely health
issue.

WPA) adalah menggerakkan anggota masyarakat lain untuk terlibat langsung dalam upaya pencegahan dan penanggulangan HIV/AIDS. Bentuk gerakan WPA ada yang formal; memiliki struktur organisasi yang baku dan rencana kegiatan yang tersusun rapi; dan ada pula yang informal; berupa aksi sukarela oleh warga dan tidak berupa organisasi.

Di Kota Bandung, gerakan WPA berbentuk gerakan informal dan aksi sukarela. Gerakan ini telah muncul sejak 2006, jauh sebelum konsep Warga Peduli AIDS digagas secara resmi oleh Komisi Penanggulangan AIDS Nasional. Sejumlah warga memulai aksi yang meliputi 1) partisipasi dalam kegiatan pencegahan HIV dan AIDS yang diselenggarakan oleh Komisi Penanggulangan AIDS dan LSM HIV; 2) penyebarluasan informasi mengenai HIV dan AIDS dan pencegahannya; serta mempromosikan anti stigma dan anti diskriminasi pada ODHA ke masyarakat luas; 3) membantu Orang Dengan HIV/AIDS (ODHA) mengakses pengobatan gratis di rumah sakit pemerintah. Para warga ini 
menamai aksi mereka 'Warga Peduli AIDS' dan mereka pun menyebut diri mereka kader WPA. Para kader ini adalah para ibu rumah tangga yang telah lama aktif sebagai kader kesehatan di wilayah tempat tinggal mereka. Sebagian besar dari mereka tidak memiliki keluarga yang terinfeksi HIV/AIDS. Namun, mereka tetap memiliki kepedulian yang sangat tinggi pada masalah HIV dan AIDS (Herawati, 2017).

Aksi yang dilakukan para kader WPA di Kota Bandung sangat menarik untuk diteliti. Sebab, di saat sebagian besar masyarakat Indonesia memiliki pandangan negatif dan stigma pada HIV, AIDS, dan ODHA, para kader ini justru sangat peduli dan tergerak untuk berpartisipasi dalam upaya pencegahan dan penanggulangan. Selain itu, sebagian besar kader WPA adalah warga menengah ke bawah dengan kondisi keuangan rumah tangga yang sangat terbatas. Namun, keterbatasan itu tidak menghalangi mereka untuk melakukan aksi sukarela.

Volunterisme atau kesukarelawanan merujuk pada pekerjaan, aktivitas atau aksi yang dilakukan individu atau kelompok secara sukarela, tidak berbayar, dengan tujuan mewujudkan kondisi yang lebih baik dan bermanfaat di masyarakat (Ibrahim, 2017). Penelitian-penelitian sebelumnya mengenai kesukarelawanan (volunterisme) menemukan beragam faktor yang memotivasi individu atau kelompok melakukan aksi tersebut. Aksi sukarela tidak selalu murni didasari oleh altruisme tetapi juga oleh kepentingan pribadi (Omoto dan Snyder, 2002; Grönlund, 2013). Faktor sosial, budaya, dan psikologis adalah faktor yang umum memotivasi aksi sukarela (Clary, Snyder, dan Ridge, 1992; Clary et al., 1998; Esmond dan Dunlop, 2004; Akintola, 2011; Grönlund, 2013; Novoa dan Johnson, 2013).

Clary dan Snyder (1999) menjelaskan enam faktor yang secara umum memotivasi individu atau kelompok melakukan aksi sukarela. Pertama, faktor sosial-budaya. Individu atau kelompok melakukan aksi sukarela karena ingin menerapkan nilai dan norma sosial-budayaagama mereka. Kedua, faktor karir. Individu atau kelompok melakukan aksi sukarela dengan tujuan membangun jejaring sosial dengan sesama volunteer dan jejaring itu dimanfaatkan untuk meningkatkan karir mereka. Ketiga, faktor personal. Individu melakukan aksi sukarela karena memiliki masalah pribadi dan ingin rehat sejenak dari persoalan pribadi mereka. Keempat, faktor permasalahan sosial. Indvidu melakukan aksi sukarela karena ingin memahami permasalahan sosial di masyarakat. Kelima, faktor kepercayaan diri. Individu melakukan aksi sukarela dengan tujuan membangun kepercayaan diri karena merasa dibutuhkan oleh orang lain. Keenam, faktor pengakuan. Individu melakukan aksi sukarela karena ingin memperoleh pengakuan atas ketrampilan yang ia miliki.

Senada dengan temuan Clary dan Snyder
(1999), penelitian Grönlund dkk (2013); Parboteeah, Cullen, dan Lim, (2004) juga menemukan bahwa faktor budaya menjadi faktor yang mendorong individu melakukan aksi sukarela. Masyarakat di dunia sebagian besar adalah masyarakat komunal dan kolektif. Jiwa altruisme di masyarakat komunal sangat dianjurkan. Oleh karena itu banyak warga masyarakat komunal yang terdorong melakukan aksi sukarela karena hal itu merupakan bagian dari ekspresi budaya mereka (Hofstede, 2001; Novoa dan Johnson, 2013).

Penelitian Essen, Hustinx, Haers, dan Mels, (2015) dan penelitian Okun, O'Rourke, Keller, Johnson, dan Enders (2015) pada motivasi aksi sukarela, menemukan faktor lain yang memotivasi individu melakukan aksi sukarela, yaitu faktor agama. Di setiap agama, terdapat anjuran mengembangkan sifat altruisme dan kepedulian pada orang lain. Menolong orang lain adalah cerminan ketaatan umat pada ajaran agama.

Di dalam konteks epidemi HIV dan AIDS, penelitian Akintola (2011) di Afrika, menemukan bahwa aksi sukarela lebih banyak dimotivasi oleh faktor agama. Kegiatan sukarela di bidang HIV dan AIDS di Afrika umumnya dilakukan oleh orangorang Kristen yang taat dan dilakukan dalam payung gereja. Para sukarelawan meyakini bahwa aksi kepedulian mereka pada Orang dengan HIV/AIDS adalah salah satu upaya mereka mewujudkan cinta kasih dan ketaaatan pada Tuhan.

Penelitian ini bertujuan: 1) menelusuri dan menggambarkan motivasi para kader WPA di Kota Bandung melakukan aksi kesukarelawanan dalam pencegahan dan penanggulangan HIV dan AIDS; 2) menelusuri dan menggambarkan makna aksi tersebut bagi kader; dan 3) menggambarkan manfaat dari aksi volunterisme tersebut bagi orang dengan HIV dan AIDS serta masyarakat umum yang menjadi sasaran aksi.

\section{B. METODE PENELITIAN}

$\mathrm{P}$ enelitian ini dilakukan dengan metode kualitatif model etnografi. Data primer dikumpulkan melalui wawancara mendalam dan pengamatan terlibat. Wawancara dilakukan pada para kader WPA di lima kecamatan di Kota Bandung yaitu Rancasari, Sumur Bandung; Kebon Gedang, Kebon Pisang, dan Bojongloa Kidul. Pengamatan terlibat dilakukan pada seluruh aksi yang dilakukan oleh kader WPA. Data sekunder dikumpulkan dari studi-studi arsip. Analisis data dilakukan mengikuti prinsip analisis data kualitatif, yaitu analisis tematik. Hasil penelitian disajikan dengan model deskriptif eksplanatoris (Syahrizal, 2016) dengan menonjolkan aspek emik (Miles dan Huberman, 2014; Amady, 2015). Penelitian ini 
dilakukan pada kurun waktu Juni-Desember 2015 dan Februari-Juni 2016; dan telah dinyatakan Iolos uji etik oleh komite etik Australian National University. Identitas para kader ditampilan dengan nama asli sesuai permintaan mereka dan nama para ODHA menggunakan nama samaran.

\section{HASIL DAN PEMBAHASAN}

\section{Epidemi HIV di Kota Bandung dan Aksi Sukarela Warga}

$\mathrm{T}$ ingginya prevalensi infeksi HIV dan AIDS Kota Bandung saat ini, terkait erat dengan tren penggunaan narkoba suntik berbahan putaw (heroin berkualitas rendah) pada awal tahun 2000. Putaw digunakan dengan cara disuntik melalui pembuluh darah balik. Harga jarum suntik yang mahal dan rumitnya ijin untuk membeli jarum suntik di apotik memunculkan perilaku bergantian menggunakan jarum suntik diantara para pengguna narkoba suntik (penasun). Perilaku ini mendorong tersebarnya virus HIV secara cepat di kalangan penasun. Beberapa tahun kemudian, ledakan infeksi HIV melanda Indonesia termasuk Kota Bandung. Pasangan seksual para penasun pun mulai terjangkit HIV; begitupun bayi-bayi yang terlahir dari mereka.

Pada awal 2006, program penanggulangan HIV yang didanai oleh lembaga kesehatan internasional mulai masuk ke Kota Bandung. Perkumpulan Keluarga Berencana Indonesia (PKBI) cabang Jawa Barat adalah salah satu lembaga yang pertama melaksanakan program penanggulangan HIV dan AIDS di Bandung. Program itu bernama Harm Reduction (HR)PKBI; didanai oleh Australian Aid (Ausaid). Tujuan program itu adalah menjangkau dan memberi edukasi mengenai pengurangan dampak buruk narkoba dan HIV pada penasun. Program ini juga menggandeng para kader kesehatan di Kota Bandung untuk berpartisipasi dalam upaya pencegahan dan penanggulangan di wilayah tempat tinggal masing-masing. Saat diajak oleh tim HR-PKBI itulah pertama kali para kader kesehatan di Kota Bandung mengenal isu HIV dan AIDS. Mereka pun tersadar akan gentingnya situasi epidemi HIV di Bandung dan tergerak berpartisipasi dalam aksi pencegahan yang dilakukan oleh LSM HIV dan juga Komisi Penanggulangan AIDS Kota Bandung.

Beberapa kader kesehatan di Kota Bandung yang peduli pada isu HIV dan AIDS dan aktif dalam aksi pencegahan, bertemu di dalam sebuah acara peringatan hari AIDS sedunia di akhir 2006. Di acara itu, mereka mendeklarasikan aksi mereka sebagai aksi Warga Peduli AIDS dan menyebut diri mereka kader Warga Peduli AIDS. Mereka mengajak warga masyarakat lain untuk turut serta dalam aksi mereka. Tahun demi tahun, makin banyak warga yang mulai peduli pada masalah HIV dan tergerak melakukan aksi sebagai warga peduli AIDS.

Kemunculan aksi WPA di setiap wilayah dilatarbelakangi persitiwa yang berbeda-beda. Secara umum aksi dilatarbelakangi oleh rasa keprihatinan para kader kesehatan pada isu HIV dan AIDS setelah mengetahui beberapa tetangga mereka terinfeksi HIV. Misal, di Kecamatan Sumur Bandung, munculnya aksi Warga Peduli AIDS dilatarbelakangi oleh insiden meninggalnya tiga warga secara berturut-turut pada pertengahan 2010 akibat AIDS. Insiden itu mendorong kader kesehatan setempat untuk mencari info lebih lanjut mengenai AIDS dan mulai melakukan aksi pencegahan. Mereka mendekati warga yang mereka ketahui sebagai penasun dan membujuknya mengikuti konseling dan tes HIV di Klinik Perkumpulan Keluarga Berencana Indonesia (PKBI) yang menyediakan layanan konseling dan tes HIV gratis. Penasun yang telah terinfeksi HIV didampingi untuk mengakses layanan pengobatan gratis di rumah sakit. Selain itu, kader WPA juga mendekati dan memberikan pengertian pada keluarga ODHA agar tidak mengucilkan dan tetap memberikan dukungan dan perawatan pada anggota keluarganya tersebut.

Fenomena kemunculan aksi WPA di Bandung berbeda dengan temuan penelitian sebelumnya di beberapa wilayah Indonesia. Penelitian sebelumnya menyebutkan bahwa faktor pengetahuan yang cukup mengenai epidemi HIV menjadi faktor pendorong warga melakukan aksi pencegahan melalui WPA beraksi (Fernandez, Manurung, Toy, dan Ndoen, 2019; Wati, Cahyo, dan Indraswari, 2017). Sementara di Kota Bandung, peristiwa terkait HIV dan AIDS di wilayah tempat tinggal menjadi motivasi warga untuk beraksi.

\section{Budaya Sunda, Agama, dan Volunterisme}

'Sunda' adalah istilah yang merujuk pada etnis, budaya, dan bahasa suku asli di Jawa Barat. Suku Sunda adalah suku terbesar nomor dua di Indonesia setelah suku Jawa. Di Kota Bandung, 93\% populasi penduduk adalah orang Sunda. Secara historis, orang Sunda bermata pencaharian sebagai petani peladang berpindah dan hidup dalam kelompok-kelompok kecil. Kebiasaan hidup secara berkelompok membuat orang Sunda mengembangkan tradisi komunalisme dan sangat menjunjung tinggi nilai kebersamaan; kerukunan, dan sifat saling menolong (Harsojo, 1979) .

Orang Sunda sangat religius dan memiliki jiwa spiritualisme tinggi. Status sosial individu tidak hanya dilihat dari tingkat pendidikan saja, tetapi juga dari kemampuannya menerapkan nilai-nilai dan norma-norma kesundaan, diantaranmya 
religius dan berperilaku halus (Sudaryat, 2014; Danasasmita, 1987; Warnaen, 1987). Budaya demikian masih dijunjung tinggi dan dipelihara oleh masyarakat Sunda (Rosidi, 2010).

Agama asli orang Sunda adalah Sunda wiwitan; yaitu agama penghormatan pada leluhur dan kekuatan alam. Agama ini mendapat pengaruh dari Hindu dan Budha pada abad ke-4; dan pengaruh Islam pada abad ke-17. Islam memiliki pengaruh yang paling kuat pada religi asli orang Sunda. Ritual-ritual religi masa praIslam kini telah banyak ditinggalkan dan digantikan oleh ritual Islam (Ricklefs, 2012). Konon, kemiripan ajaran Islam dan agama asli Sunda yang mengedepankan pentingnya komunalisme (berjamaah) membuat orang Sunda sangat mudah menerima ajaran Islam (Ekadjati, 2005). Kini, Islam adalah agama mayoritas orang Sunda. Di Kota Bandung, 87\% populasinya beragama Islam (Badan Pusat Statistik Kota Bandung, 2017).

Perpaduan kuat antara Islam dan Sunda terlihat dari ungkapan 'Islam teh Sunda, Sunda teh Islam' atau 'Islam adalah Sunda dan Sunda adalah Islam' (Newland, 2000; Jakob, 2010; Wibisana, 2010; Wildan, 2010). Menjadi Islam dan menjadi Sunda adalah dua identitas penting orang Sunda (Newland, 2000). Konsekuensinya, orang Sunda berupaya menerapkan nilai dan norma Sunda dan Islam secara bersamaan di dalam kehidupan sehari-hari. Oleh karena itu, setiap perilaku individu Sunda selalu dianjurkan untuk mengakar pada agama dan budaya (Rusyana, 1989; Ekadjati, 2005; Kahmad, 2009).

Kolektivisme dan komunalisme adalah elemen penting dalam organisasi sosial masyarakat Sunda; sedangkan individualisme sangat tidak dianjurkan. Nilai-nilai dan moralitas kesundaan tertulis di kitab Sanghyang Siksakandang Karesian, sebuah kitab pedoman sikap dan prinsip hidup bagi para pandita (resi) yang ditulis pada abad 15. Orang Sunda secara umum juga sangat dianjurkan untuk mempelajari dan menjalankan prinsip-prinsip yang tertulis di kitab tersebut agar bijaksana (Noorduyn dan Teeuw, 2006).

Nilai dan moralitas kesundaan dilestarikan turun temurun di masyarakat Sunda melalui nyanyian rakyat, perumpamaan, kiasan, dan kata pepatah dalam Bahasa Sunda yang menegaskan pentingnya menjaga kerukunan, menjaga perilaku, dan solidaritas pada sesama. Hal ini tampak dalam ungkapan silih asah, silih asih, dan silih asuh yang bermakna saling belajar, saling mengasihi, dan saling mengasuh yang merupakan konsep dasar dalam interaksi sosial orang Sunda (Sumamiharja, 2005).

Sikap suka menolong orang lain sangat disarankan dalam budaya Sunda. Hal ini tampak dalam ungkapan: 'kedah nulung kanu butuh, nalang kanu susah, ngobor kanu poeken, mere kanu weleh, nganterkeun kanu sieun' yang artinya 'mesti menolong orang yang membutuhkan, menolong orang yang kesusahan, memberikan penerangan pada orang mengalami kegelapan, dan menemani orang yang memerlukan kawan atau dukungan (Indrawardana, 2014; Lisdiati, Hum Syarif Hidayat, Abdulhak, dan Muchsin, 2014; Pasaribu, 2015).

Di dalam budaya Sunda, sikap sukarela dan suka menolong adalah cerminan tingkat spiritualisme, kebijakan, intelektualitas, kematangan emosi, dan ketrampilan hidup individu yang sangat tinggi. Individu dengan karakteristik demikian dianggap sebagai sosok manusia Sunda seutuhnya, yaitu manusia yang bermanfaat bagi orang lain (Sudaryat, 2014).

\section{Motivasi dan Makna Volunterisme}

Berdasarkan hasil wawancara dengan para kader Warga Peduli AIDS, mereka memaknai aksi mereka sebagai 1) ibadah, 2) sedekah ilmu, 3) wujud tanggungjawab sosial pada masyarakat; dan 4) upaya menjadi manusia yang bermanfaat di masyarakat.

\section{1) Aksi sebagai Ibadah}

Aksi Warga Peduli AIDS tidak menghasilkan keuntungan finansial maupun material bagi para kader. Mereka justru harus mengorbankan uang pribadi, waktu, dan energi mereka untuk menjalankan aksi sukarela itu. Mereka seringkali menggunakan uang yang seharusnya untuk keperluan dapur mereka sebagai ongkos transport menghadiri pelatihan pencegahan HIV atau mengantar tetangga yang ODHA untuk mengambil obat di rumah sakit. Hal ini dialami oleh Ratna, salah seorang kader kesehatan di Kecamatan Sumur Bandung yang memulai aksi sebagai kader WPA sejak 2010. Ratna kini menjadi pendamping pengobatan bagi tiga tetangganya yang ODHA. Setiap bulan ia menemani ketiganya mengambil obat ke rumah sakit, dan mendampingi mereka jika harus dirawat inap.

Ratna adalah ibu rumah tangga yang tidak memiliki penghasilan. Satu-satunya pendapatan keluarganya berasal dari gaji suaminya yang bekerja sebagai pegawai sablon. Gaji itu hanya cukup untuk makan dan kebutuhan sekolah dua anaknya yang duduk di bangku SD dan SMP. Terkadang, Ratna pun harus berhutang pada tetangga untuk mencukupi kebutuhan sehari-hari. Namun, kondisi keuangan rumah tangganya tidak menghalanginya untuk melakukan aksi sukarela sebagai WPA.

Ratna menyebutkan bahwa ia tergerak menolong tetangga yang ODHA tidak semata karena kewajibannya sebagai kader kesehatan, tetapi karena rasa kemanusiaan dan kewajiban sebagai seorang Muslim. Baginya, menolong orang lain adalah bagian dari ibadah dan ia tidak merasa terbebani dengan kewajiban itu:

"Hidup di dunia kan cuma sebentar saja. Kita 
mesti perbanyak ibadah, agar dapat pahala untuk di akhirat nanti. Ibadah kan gak hanya sholat. Berbuat baik juga ibadah. Di WPA ini saya juga ibadah. Saya jalankan dengan ikhlas. Ibadah saya di WPA ini hanya mengharap PGA (Pahala Gusti Allah; (Ratna; kader WPA di Kecamatan Sumur Bandung).

Di dalam aksinya, Ratna tidak mempedulikan latar belakang sosial orang yang ditolongnya. la mengakui bahwa pada dasarnya ia tidak suka dengan perilaku tetangganya yang ODHA saat mereka masih jadi penasun. Sebab, para penasun di wilayah tempat tinggalnya, kerap mencuri untuk mendapatkan uang guna membeli putaw. la pun kerap kali menjadi korban aksi pencurian itu. Namun, saat para mantan penasun itu telah menjadi ODHA, Ratna tetap bersedia membantu mereka. Baginya, semua orang yang layak ditolong harus ditolong, terlepas dari latarbelakang sosialnya atau masa lalunya. la menyebut bahwa aksinya sejalan dengan konsep silih asih dalam budaya Sunda, yang artinya saling mengasihi.

Penuturan Ratna menggambarkan bahwa ia membangun makna bagi aksinya dengan cara mengkaitkannya dengan konsep ibadah. Baginya, konsep ibadah tidak hanya merujuk pada ritual berdoa semata, yaitu sholat, tetapi juga merujuk pada semua bentuk tindakan yang bertujuan baik dan sesuai dengan ajaran agama yang dianutnya, termasuk menolong ODHA.

\section{2) Aksi sebagai 'sedekah ilmu'}

Kegiatan yang dilakukan para kader WPA, selain menjadi pendamping ODHA, adalah menyampaikan informasi mengenai HIV dan AIDS pada para tetangga mereka; serta mengajak masyarakat luas untuk tidak mengucilkan ODHA. Para kader memanfaatkan pertemuan rutin di masyarakat, sebagai arena menyampaikan informasi. Hal ini dilakukan oleh Euis Farida, adalah salah satu kader WPA di Kecamatan Kebon Gedang.

Serupa dengan Ratnawati, kondisi keuangan rumah tangga Euis sangat terbatas. Suaminya tidak memiliki pekerjaan tetap. Euis berjualan gorengan untuk mendapatkan tambahan pendapatan untuk keperluan hidup sehari-hari.

Euis memulai aksinya sejak akhir 2012. Bersama kader lain, ia secara berkala menghadiri acara majelis taklim, PKK, Posyandu, dan karang taruna di wilayah tempat tinggalnya. Di setiap acara itu, Euis dan kader WPA lain meminta waktu pada penyelenggara acara agar diijinkan menyampaikan informasi mengenai HIV dan AIDS selama 15 menit di akhir acara.

Euis menyatakan bahwa aksinya tidak hanya dilandasi oleh kepeduliannya pada masalah HIV tetapi juga oleh keyakinannya bahwa aksinya sesuai dengan anjuran dalam agamanya untuk berbagi ilmu. la menyebut aksinya sebagai sedekah ilmu:

"Sedekah kan gak hanya dengan uang dan harta. Pengetahuan dan ilmu itu kan juga harta. Jadi bisa disedekahkan juga. Kalau ilmu yang kita sedekahkan itu bermanfaat buat orang lain, kita dapat pahala. Saya uang gak punya, saya hanya punya sedikit info tentang HIV, ya sudah, saya sebarin aja. Saya anggap ini sedekah saya. Lagipula sedekah ilmu itu kan jadi amal jariyah, nggak akan terputus pahalanya sampai kita mati nanti (Euis Farida; kader WPA di Kecamatan Kebon Gedang).

Selain menganggap penyebarluasan informasi sebagai sedekah ilmu. Euis juga menganggap aksinya sebagai perwujudan nilai-nilai silih asah dalam budaya Sunda. Melalui diskusi saat menyampaikan informasi, ia mengaku mendapatkan pengetahuan tambahan saat para tetangga juga memiliki informasi yang ia belum mengetahuinya. Pada tahap itulah saling asah terjadi. Dengan demikian, selain mengakarkan aksinya pada nilai agama; Euis juga mengakarkan aksinya pada nilai budaya Sunda.

\section{3) Aksi sebagai wujud tanggungjawab sosial}

Para kader menyebut bahwa aksi mereka merupakan perwujudan rasa tanggungjawab sosial. Mereka melihat masalah HIV dan AIDS sebagai masalah bersama dan sebagai warga mereka terpanggil untuk turut menyelesaikan masalah itu. Hal ini diyakini oleh Ira Canra, kader WPA di Kecamatan Rancasari.

Ira adalah satu dari kader WPA yang berasal dari kelompok sosial menengah. Suami Ira adalah salah satu staf di Komisi Penanggulangan AIDS Provinsi Jawa Barat. Ira menjabat sebagai sekretaris PKK dan Ketua RW Siaga di Kecamatan Rancasari. Meski suaminya telah berkecimpung di dunia HIV dan AIDS sejak lama, Ira tidak serta merta tergerak untuk mengetahui lebih dalam mengenai hal itu apalagi beraksi. la baru tergerak beraksi pada akhir 2012 setelah menyaksikan testimoni salah seorang tetangganya yang ternyata seorang ODHA dan mantan penasun. Testimoni itu dilakukan pada sebuah acara sosialisasi HIV dan AIDS yang diselenggarakan oleh Komisi Penanggulangan AIDS di kantor Kecamatan Rancasari. Testimoni itu membuat Ira menyadari dekatnya masalah epidemi itu dengan kesehariannya. Lambat laun, Ira pun makin mengetahui bahwa tak sedikit warga muda di wilayah tempat tinggalnya adalah mantan penasun dan ODHA. Selaku aktivis kesehatan, rasa tanggungajawab sosialnya pun tergerak. la pun memasukkan kegiatan penyebarluasan informasi mengenai HIV dan AIDS di dalam agenda kegiatan PKK dan RW Siaga yang dipimpinnya. 
Target penerima informasi Ira awalnya adalah para tetangga satu wilayah RT-nya. Lambat laun, Ira melebarkan target pada tetangga di wilayah RT dan RW lain. Di dalam aksinya, ia menemukan bahwa banyak anak muda di wilayahnya yang mantan penasun dan telah HIV positif telah lama mengalami pengucilan; dan mereka ingin kembali diterima oleh masyarakat. Ira tanpa ragu merangkul mereka dan mengajak mereka bersamanya mempromosikan anti stigma pada ODHA. Ira menyatakan:

\section{"Saya merasa bertanggungjawab membantu mereka yang ingin kembali menjadi warga yang baik. Ya...meski mereka dulu penasun, tapi sekarang kan sudah enggak. Bagaimana pun mereka kan tetangga kita, anak-anak kita juga. Mereka bahkan bisa membantu kita dalam aksi pencegahan"(Ira Canra, kader WPA di Kecamatan Rancasari).}

Ira mengkaitkan aksinya dengan nilai-nilai dalam Islam. la tidak secara tegas menyebutkan ingin mendapatkan pahala dari aksinya, tetapi ia menyatakan bahwa aksinya di WPA telah membuatnya melatih diri menjadi orang ikhlas. la ikhlas memberikan waktu, tenaga, dan keuangan bagi aksinya. la menyatakan cukup bahagia dengan gaji SAJUTA yang ia peroleh. la menjelaskan lebih lanjut bahwa SAJUTA adalah singkatan dari sabar, jujur, dan tawakkal.

Di Kecamatan Sumur Bandung, Yulia dan Wawang adalah dua kader yang memiliki kerabat ODHA. Mereka menyatakan bahwa pengalaman memiliki kerabat ODHA membuat mereka tergerak untuk mencegah keluarga lain memiliki pengalaman yang sama dengan mereka. Mereka menyatakan bahwa aksi mereka adalah perwujudan tanggungjawab sosial mereka.

Wawang, memiliki adik kandung yang mantan penasun dan kini menjadi ODHA. la dan keluarganya tidak mengusir adiknya, meski mereka kecewa adiknya menjadi penasun. Saat Wawang mengetahui adiknya terinfeksi HIV, ia mencari semua teman-teman adiknya yang ia ketahui pernah menyuntik narkoba bersama dengan adiknya. Wawang mendekati mereka satu demi satu dan memberi mereka penjelasan mengenai HIV dan AIDS. Wawang juga membujuk dan mendampingi mereka untuk mengikuti konseling dan tes HIV di PKBI. Wawang menyatakan bahwa tindakan itu ia lakukan karena ia merasa bertanggungjawab pada kesehatan teman-teman adiknya:

\footnotetext{
"Saya merasakan betul tidak tahu apa-apa tentang HIV waktu pertama adik saya kena AIDS. Bingung harus bagaimana; dan takut juga. Pengalaman itu bikin saya merasa bersalah kalau teman-teman adik saya sampai tidak tahu bahaya yang mengancam diri mereka. Mereka juga "kan para tetangga saya. Saya merasa
}

bertanggungjawab untuk memberitahu mereka mengenai HIV (Wawang, kader WPA Kecamatan Sumur Bandung).

Yulia, kader WPA di Kecamatan Sumur Bandung memiliki dua keponakan yang mantan penasun dan kini menjadi ODHA. Serupa dengan Wawang, pengalaman merawat kerabat ODHA membuat mereka merasa memiliki tanggungjawab sosial untuk mencegah keluarga lain di wilayahnya mengalami hal yang sama dengan keluarga mereka. Yulia dan Wawang secara intensif mendekati para tetangga yang mereka ketahui pernah menggunakan narkoba bersama kerabatnya. Mereka secara perlahan memberikan informasi mengenai HIV dan AIDS dan juga dengan sabar membujuk dan mendampingi mereka untuk konseling dan tes HIV. Mereka juga mendampingi para tetangga yang hasil tes HIV-nya positif, untuk mendapatkan pengobatan di rumah sakit.

\section{4) Aksi sebagai upaya menjadi manusia bermanfaat}

Para kader WPA seringkali menyatakan bahwa mereka melakukan aksi dengan tujuan mendatangkan manfaat bagi masyarakat luas. Dengan cara itu, mereka pun menjadi manusia yang bermanfaat bagi masyarakat luas. Hal ini diakui oleh Iwa Lesmana, kader WPA di Kecamatan Bojongloa Kidul.

Iwa adalah satu-satunya kader WPA laki-laki di Kota Bandung. Sehari-hari ia adalah staf bagian keagamaan di kecamatan. la juga berprofesi sebagai ustadz yang membina majelis taklim di wilayah Kecamatan Bojongloa Kidul. Oleh karena ia sering menyelipkan informasi mengenai pencegahan HIV dan AIDS di selasela acara majelis taklim serta aktif dalam acara talkshow HIV di radio. Iwa dikenal dengan sebutan 'ustadz HIV' karena aksinya itu.

Iwa memulai aksi sebagai kader warga peduli AIDS pada tahun 2011. Sebelum tahun itu, Iwa sama sekali tidak pernah peduli dengan isu HIV dan AIDS. Bahkan ia memiliki stigma tinggi pada para ODHA. Menurutnya, orang dengan perilaku melanggar aturan agama layak diberi teguran berupa penyakit. la selalu menganggap bahwa ODHA layak mendapatkan hukuman berupa penyakit akibat perbuatan mereka yang menyimpang dari norma sosial dan agama.

Pandangan Iwa pada isu HIV dan ODHA berubah drastis saat ia menyaksikan testimoni dari seorang perempuan ODHA di sebuah acara sosialisasi mengenai HIV di kantor Komisi Penanggulangan AIDS Kota Bandung. la hadir di acara itu mewakili atasannya yang berhalangan hadir.

Perempuan yang melakukan testimoni di acara itu adalah seorang ibu rumah tangga muda dengan seorang anak balita. Suaminya baru saja 
meninggal akibat AIDS. Saat suaminya didiagnosa AIDS, dokter yang merawat suaminya menganjurkan ia dan anaknya yang masih balita untuk di tes HIV. Hasilnya, ia dan anaknya positif terinfeksi HIV.

Testimoni itu mengubah pandangan Iwa pada ODHA dan isu HIV dan AIDS secara umum. Awalnya, ia menganggap bahwa semua ODHA layak mendapat penyakit karena perbuatan mereka yang melanggar norma agama, seperti homoseksualitas, menggunakan narkoba suntik atau menjadi pekerja seks. Namun, ketika ia mengetahui bahwa penyakit itu dapat menyerang siapa saja, ia menyadari bahwa anggapannya itu keliru. Iwa juga merasa bersalah telah abai pada isu HIV dan AIDS tanpa pernah melakukan tabayun (mencari kebenaran sebuah informasi); dan berprasangka buruk pada ODHA. la pun tersadar bahwa seharusnya sebagai pemuka agama, ia turut berkontribusi pada upaya menyelesaikan masalah itu.

Sejak menyadari peran yang seharusnya ia lakukan, Iwa aktif dalam setiap kegiatan pelatihan pencegahan HIV dan AIDS. la membaca semua buku panduan dan brosur mengenai HIV dan AIDS. Tak jarang ia juga berdiskusi para aktivis di LSM HIV maupun para staf Komisi Penanggulangan AIDS di Kota Bandung untuk memperdalam pengetahuannya. la mengakui bahwa hal itu dilakukannya dalam rangka tabayun.

Iwa kini aktif sebagai kader Warga Peduli AIDS. la memaknai aksinya sebagai sebuah upaya mengajak masyarakat berbuat kebaikan:

"Di dalam Islam kan kita dianjurkan melakukan
amar ma'ruf nahi munkar. Itu ditulis jelas di
Al Qur'an surat Lukman 17. Menurut saya
apa yang saya lakukan ini adalah bukti
bahwa saya ingin melakukan hal-hal baik;
dan saya juga mengajak orang-orang untuk
bersama saya melakukan hal-hal baik." (Iwa
Lesmana, kader WPA di Kecamatan
Bojongloa Kidul).

Aksi sebagai kader WPA membuat Iwa berinteraksi secara intensif dengan ODHA. Banyak dari ODHA yang ia temui memiliki masa lalu sebagai penasun, pekerja seks, dan penyuka sesama jenis. Saat menjadi ODHA, orang-orang itu meminta Iwa membantu mereka belajar agama di sisa hidup mereka. Iwa pun membantu mereka belajar sholat dan membaca Al-Quran. Lambat laun, Iwa menjadi sangat dekat dengan mereka dan ia secara sukarela menjadi pendamping mereka dalam memepelajari agama. Iwa menyadari bahwa aksi sukarelanya sungguh bermanfaat bagi orang lain.

Iwa mengakui bahwa aksinya sebagai kader WPA mendampingi ODHA memberikan kepuasan tersendiri baginya. Menurutnya, aksi yang ia lakukan lebih memuaskan hatinya daripada berceramah di depan umum. Saat ceramah, ia mengajak masyarakat berbuat hal baik tetapi ia tidak dapat melihat langsung efek dari ceramahnya; apakah betul orang yang ia ceramahi menjalankan anjurannya atau tidak. Sementara di aksi WPA, ia dapat melihat langsung hasil dari aksinya itu. la sering menyaksikan orang-orang yang bertobat dan kembali pada ajaran agama secara sukarela; yaitu saat ia mendampingi para mantan pecandu menjalani proses pertobatan dan secara bertahap belajar sholat dan membaca Al-qur'an. la merasa puas saat orang-orang yang ia dampingi menemukan kembali semangat hidup.

Selain memaknai aksinya sebagai upaya mengajak orang lain berbuat baik, Iwa juga menganggap aksinya sebagai upayanya menjadi manusia yang bermanfaat:

"Ya, saya ingin-lah menjadi manusia yang bermanfaat. Rasulullah bersabda: khairunnasi anfa'uhum lilnas, sebaik-baiknya orang adalah yang mendatangkan manfaat bagi orang lain, yaitu masyarakatnya. Semoga saya apa yang saya lakukan ini selalu bermanfaat buat orang lain (Iwa Lesmana, kader WPA di Kecamatan Bojongloa Kidul).

Iwa menyadari bahwa aksi sukarela yang ia lakukan, tidak mendatangkan keuntungan keuangan dan materi. Bahkan ia seringkali harus mendonasikan uang pribadi dan waktu untuk melakukan aksi itu. Namun, ia ikhlas karena ia merasa dengan cara itu ia dapat menjadi manusia bermanfaat.

Diantara beragam faktor yang mendorong individu melakukan aksi kesukarelawanan di penelitian sebelumnya, pada kasus warga peduli AIDS di Kota Bandung, faktor keinginan menerapkan nilai agama dan budaya adalah faktor yang paling kuat. Hal ini berbeda dengan dengan di tempat lain di Indonesia, di mana faktor pengetahuanlah yang menjadi faktor terkuat yang mendorong warga untuk memulai gerakan WPA.

Makna aksi sukarela yang dilakukan warga di bangun dengan cara menghubungkan aksi mereka dengan nilai-nilai budaya dan agama. Aksi sukarela bagi para kader adalah ekspresi religuisitas dan budaya mereka.

\section{Aksi Volunterisme WPA dalam pandangan Orang dengan HIV dan AIDS (ODHA) dan masyarakat umum}

Makna volunterisme bagi kader makin menguat ketika mereka mendapati bahwa aksi yang mereka lakukan memberikan manfaat bagi orang dengan HIV dan AIDS (ODHA) yang mereka dampingi. Para ODHA menyatakan bahwa aksi para kader WPA sangat berarti bagi mereka terutama dalam hal pengurangan stigma, dan rekonstruksi identitas sosial. Bayu, salah seorang mantan penasun dan ODHA menyatakan: 
"Gimana ya rasanya tuh saya sebagai orang kayak gini. Ya istilahnya mungkin orang lihat saya tuh kayak sampah kali ya. Ga ada guna, harus dibuang. Tapi pas saya diajak ibu-ibu kader WPA itu, saya ada rasa haru. Saya merasa kayak sampah, tapi yang didaur ulang gitu. Ada guna lagi" (Bayu, mantan penasun dan ODHA di Kecamatan Rancasari).

Selain merasakan manfaat dari aksi WPA, para ODHA juga memberikan apresiasi pada aksi tersebut. Serupa dengan para kader, para ODHA juga mengkaitkan aksi para WPA dengan nilainilai dalam budaya Sunda dan agama. Hal ini tampak dalam pernyataan Ela, perempuan yang tertular HIV dari suaminya:

"Saya gak bisa bales kebaikan mereka (kader WPA). Semoga Allah yang membalas kebaikan mereka. Saya dibolehin tinggal di rumah kader waktu diusir mertua gara-gara ketahuan saya HIV; didampingi waktu terpuruk. Jadi kalo dibilang WPA itu nerapin silih asih ya bener pisan. Asli itu mah (Ela; ODHA di Kecamatan Sumur Bandung).

Pernyataan Bayu dan Ela, menegaskan bahwa nilai-nilai agama dan budaya Sunda menjadi rujukan bagi kader dan juga ODHA yang didampingi oleh kader untuk membangun makna atas aksi WPA. Aksi tersebut tidak hanya bermakna bagi kader semata tetapi juga bermakna bagi para ODHA yang menerima manfaat dari aksi.

Bagi masyarakat umum non-ODHA, aksi para kader dalam menyebarluaskan informasi mengenai HIV dianggap sangat bermanfaat dan juga memiliki makna penting, seperti penuturan Usep, salah seorang warga:

"Pas saya denger penjelasan tentang HIV itu, wah kaget saya. takut. Tapi lalu saya bersyukur saya jadi tahu. Coba kalau saya nggak tahu, bisa-bisa saya berisiko kena. Makasih-lah sama mereka (kader) dah kasih info'. Mudah-mudahan sing kagantian lah (terganti) kebaikan mereka (kader)." (Usep, warga di Kecamatan Kebon Gedang)

Serupa dengan para ODHA, Usep juga memberikan apresiasi pada aksi para kader WPA. la juga menganggap bahwa aksi tersebut layak untuk mendapatkan balasan baik dari Tuhan.

\section{D.KESIMPULAN}

A ksi WPA Kota Bandung memberikan gambaran bahwa aksi sukarela dalam pencegahan HIV dan AIDS tidak selalu didorong oleh kecukupan tingkat pengetahuan warga mengenai isu HIV dan AIDS semata tetapi justru didorong oleh rasa kepedulian dan rasa tanggungjawab sosial pada masalah HIV dan AIDS. Aksi yang dilakukan oleh kelompok Warga Peduli AIDS di Kota Bandung menggambarkan sebuah bentuk volunterisme dalam konteks epidemi HIV yang dimotivasi oleh nilai-nilai agama dan budaya. Makna aksi ini pun dibangun tidak hanya oleh kader, tetapi oleh ODHA dan masyarakat umum selaku penerima manfaat aksi.

Aksi WPA di Kota Bandung dapat menjadi masukan bagi para pengampu kepentingan untuk merancang sebuah program pencegahan dan penanggulangan HIV dan AIDS yang berbasis masyarakat yang dilandasi oleh nilai-nilai sosial budaya dan agama yang merupakan elemen nilai penting di dalam masyarakat. Disain program sebaiknya tidak hanya mengedepankan peningkatan pengetahuan masyarakat mengenai epidemi sebagai faktor pendorong mereka untuk beraksi dan berpartisipasi dalam upaya pencegahan; tetapi sebaiknya mengedepankan peningkatan kesadaran masyarakat akan peran penting mereka dalam upaya pencegahan dan penanggulangan HIV dan AIDS sebagai bagian dari penerapan nilai-nilai sosial budaya dan agama.

\section{E. UCAPAN TERIMAKASIH}

$\mathrm{T}$ erima kasih pada para kader Warga Peduli AIDS, ODHA, dan warga di Kota Bandung yang telah berpatisipasi dalam penelitian ini. Terima kasih pada Prof. Kathryn M. Robinson (College of Asia and The Pacific, Australian National University (ANU)) atas komentar dan sarannya pada seluruh proses penulisan artikel ini, yang merupakan cuplikan dari disertasi saya. Terima kasih pada Kemristekdikti dan Australian National University yang telah menyediakan dukungan dana bagi terlaksanannya penelitian ini.

\section{DAFTAR PUSTAKA}

Akintola, O. (2011). What motivates people to volunteer? The case of volunteer AIDS caregivers in faith-based organizations in KwaZulu-Natal, South Africa. Health Policy and Planning. https://doi.org/10.1093/heapol/czq019 
Amady, M. R. El. (2015). Etik dan Emik pada Karya Etnografi. Jurnal Antropologi: Isu-Isu Sosial Budaya.

Badan Pusat Statistik Kota Bandung. (2017). Kota Bandung Dalam Angka 2017. Retrieved from https://bandungkota.bps.go.id/publication/2017/08/11/7cf46753e6cb9992a7e401b6/kotabandung-dalam-angka-2017.html

Clary, E. G., Ridge, R. D., Stukas, A. A., Snyder, M., Copeland, J., Haugen, J., Miene, P. (1998). Understanding and assessing the motivations of volunteers: A functional approach. Journal of Personality and Social Psychology. https://doi.org/ 10.1037/0022-3514.74.6.1516

Clary, E. G., Snyder, M., Ridge, R. (1992). Volunteers' motivations: A functional strategy for the recruitment, placement, and retention of volunteers. Nonprofit Management and Leadership. https://doi.org/10.1002/nml.4130020403

Danasasmita. (1987). Sewaka Darma (koropak 408), Sanghyang Siksakandang Karesian (koropak 630), Amanat Galunggung (koropak 632: Transkripsi Terjemahan. Bandung: Direktorat Jenderal Kebudayaan Kementrian Pendidikan dan Kebudayaan Republik Indonesia.

Ekadjati. (2005). Kebudayaan Sunda: Suatu Pendekatan Sejarah. Jakarta: Pustaka Jaya.

Esmond, J., Dunlop, P. (2004). Developing the Volunteer Motivation Inventory to assess the underlying motivational drives of volunteers in western Australia. Research Project Funded by Lotterywest Social Research Grant.

Essen, D. J. von, Hustinx, A. P. L., Haers, J., Mels, S. (2015). Religion and Volunteering: Complex, Contested and Ambiguous Relationships. Religion and Volunteering. https://doi.org/10.1007/9783-319-04585-6

Fernandez, W., Manurung, I. F. E., Toy, S. M., Ndoen, H. I. (2019). Perilaku Warga Peduli AIDS terhadap Penanggulangan HIV dan AIDS Di Kota Kupang. Husada Mahakam: Jurnal Kesehatan. https://doi.org/10.35963/hmjk.v4i8.157

Grönlund, H. (2013). Cultural Values and Volunteering: A Cross-Cultural Perspective, 71-84. https://doi.org/10.1007/978-1-4614-6952-0_6

Harsojo. (1979). Kebudayaan Sunda. In Manusia dan Kebudayaan di Indonesia.

Herawati, E. (2017). Warga Peduli AIDS': Community Participation in the HIV and AIDS Response in Bandung. MIMBAR, Jurnal Sosial Dan Pembangunan. https://doi.org/10.29313/mimbar .v33i2.2439

Hofstede, G. H. (2001). Culture's Consequences, Second Edition: Comparing Values, Behaviors, Institutions and Organizations Across Nations. In Edn, Sage Publications, Inc, Thousand Oaks. https://doi.org/10.1177/0022022110388567

Ibrahim, M. Y. (2017). Pengaruh amalan komunikasi terhadap penglibatan belia dalam kesukarelawanan. Malaysian Journal of Society and Space. https://doi.org/10.17576/geo-20171304-08

Indrawardana, I. (2014). Berketuhanan dalam Perspektif Kepercayaan Sunda Wiwitan. MELINTAS. https://doi.org/10.26593/mel.v30i1.1284.105-118

Jakob, S. (2010). Islam dan Sunda dalam Mitos: Pandangan Manusia Sunda Masa Kini dan Hubunganya dengan Islam. In M. Hasbullah (Ed.), Studi Sejarah Islam Sunda. Bandung: Fakultas Adab dan Humaniora, Universitas Islam Negeri Sundan Gunung Djati.

Kahmad, S. (2009). Agama Islam dan Budaya Sunda. In International Roundtable Discussion on Islamic Thought and Sundanese Values. Bandung.

Kementrian Kesehatan Republik Indonesia. (2013). Permenkes No 21 Tahun 2013.

Komisi Penanggulangan AIDS Nasional. (2010). Warga Peduli AIDS Perwujudan Partisipasi Masyarakat dalam Penanggulangan HIV -AIDS. Jakarta.

Lisdiati, L., Hum Syarif Hidayat, M., Abdulhak, I., dan Muchsin, M. (2014). The Tradition of Consecrating Rice in Pangandaran Sub-District. Asian Culture and History. https://doi.org/10.5539/ach.v7n1p156

Miles,M.B. Huberman, M. a. (2014). Qualitative data analysis: An expanded sourcebook (3rd ed.). Qualitative data analysis: An expanded sourcebook (2nd ed.). London: Sage Publication.

Newland, L. (2000). Under the Banner of Islam: Mobilising Religious Identities in West Java. Australian Journal of Anthropology. https://doi.org/10.1111/j.1835-9310.2000.tb00056.x

Noorduyn, J; Teeuw, A. (2006). Three Old Sundanese Poems. Leiden: KITLV.

Novoa, A.D; Johnson, V.(2013). Volunteer Experience: Understanding and Fostering Global Citizenship. New York. Retrieved from https://wp.nyu.edu/ steinhardt-appsych_opus/thevolunteer-experience-understanding-and-fostering-global-citizenship/

Okun, M. A., O'Rourke, H. P., Keller, B., Johnson, K. A., Enders, C. (2015). Value-Expressive Volunteer Motivation and Volunteering by Older Adults: Relationships With Religiosity and Spirituality. Journals of Gerontology - Series B Psychological Sciences and Social Sciences. https://doi.org/10.1093/geronb/gbu029

Omoto, A. M., Snyder, M. (2002). Considerations of community: The context and process of volunteerism. American Behavioral Scientist. https://doi.org/10.1177/0002764202045005007 
Parboteeah, K. P., Cullen, J. B., Lim, L. (2004). Formal volunteering: A cross-national test. Journal of World Business. https://doi.org/10.1016/j.jwb.2004.08.007

Pasaribu, Y. (2015). Modernization of Transportation Means and its Shift in Worldview of Traditional Community: Case Study of Sundanese Culture in Bandung. Tawarikh International Journal of Historical Study, 6(2), 237-257.

Ricklefs, M. C. (2012). Islamisation and Its Opponents in Java: A Political, Social, Cultural and Religious History, c. 1930 to the Present. University of Hawaii Press.

Rosidi. (2010). Mencari Sosok Manusia Sunda. Jakarta: Pustaka Jaya.

Rusyana, Y. (1989). Pandangan Hidup Orang Sunda: seperti Tercermin dalam Kehidupan Masyarakat Dewasa ini (Tahap II).

Sudaryat, Y. (2014). The Interpretation of Sundanese Educational Philosophy in Traditional Idiomatic Expressions. EDUCARE: International Journal for Educational Studies.

Sumamiharja, S. (2005). Organisasi dan Struktur sosial Masyarakat Sunda. In Masyarakat Sunda dan kebudayaannya. Jakarta: Girimuksi Pasaka.

Syahrizal, S. (2016). Deskripsi dan Eksplanasi dalam etnografi. Jurnal Antropologi: Isu-Isu Sosial Budaya. https://doi.org/10.25077/jantro.v17.n2.p161-174.2015

Warnaen, S. (1987). Pandangan Hidup Orang Sunda Seperti Tercermin dalam Tradisi Lisan dan Sastra Sunda: Penelitian Tahap II (Konsistensi dan Dinamika). Bandung.

Wati, N., Cahyo, K., Indraswari, R. (2017). Pengaruh Peran Warga Peduli AIDS terhadap Perilaku Diskriminatif pada ODHA. Jurnal Kesehatan Masyarakat (e-Journal).

Wibisana, W. (2010). Pengaruh Islam terhadap Budaya Sunda. In M. Hasbullah (Ed.), Studi Sejarah Islam Sunda. Bandung: Fakultas Adab dan Humaniora, Universitas Negeri Sunan Gunung Djati.

Wildan. (2010). Perjumpaan Islam dengan Tradisi Sunda. In Studi Sejarah Islam Sunda. Bandung: Fakultas Adab dan Humaniora, Universitas Negeri Sunan Gunung Djati. 